\title{
Utility of newly modified chitosan in the removal of heavy metal ions from aqueous medium: ion selectivity, XPS and TGA
}

\author{
OTHMAN AL-FULAIJ, ABDEL-ZAHER ABDELAZIZ ELASSAR* \\ and FAKHARIA ALSAGHEER \\ Chemistry Department, Faculty of Science, Kuwait University, P.O. Box 5969, Safat 13060, Kuwait \\ *Author for correspondence (aelassar@yahoo.com)
}

MS received 19 January 2019; accepted 5 May 2019

\begin{abstract}
The purpose of this study is to evaluate the newly prepared modified chitosan, a new environmentally friendly adsorbent, in the field of wastewater treatment. Chitosan (CS) reacted with 3-chloro-2,4-pentanedione to give CS derivatives, CS-CPD. Modified CS with $\mathrm{O}-\mathrm{O}$ and $\mathrm{N}-\mathrm{O}$ chelating centres was treated with aqueous solution containing different metal ions to investigate its metal uptake and selectivity. The concentration of metal ions in aqueous solution was measured by inductively coupled plasma-optical emission spectrometry. The structure of the complex was identified by elemental analysis, infrared and solid-nuclear magnetic resonance. In addition, the chelating centres were determined by X-ray photoelectron spectroscopy. The morphology of the modified polymer and its metal complexes was studied to show a dramatic change in cases of the CS-CPD-Pb, CS-CPD-Hg, CS-CPD-Cr and CS-CPD-Co complexes.
\end{abstract}

Keywords. Chitosan; metal removal; ion selectivity; XPS; TGA.

\section{Introduction}

Modifications of chitosan (CS) to increase its efficiency as a ligand have received considerable attention in the past few decades [1-6]. On the other hand, CS-metal complexes have attracted great interest due to their potential use in environmental treatment, agriculture, medicine and food industries [7-17]. Industrial and mining wastewater is important sources of pollution of heavy metals [18]. The polluting and toxic heavy metals in wastewater from different sources, such as industrial effluents, mine waters, water supplies and their removal have received much attention recently. The heavy metal sources to the environment have a serious threat to the environment $[19,20]$. Heavy metals, as well known, are not biodegradable and accumulate in living organisms causing different diseases and disorder. It has been reported that the presence of heavy elements in drinking water causing many diseases such as bladder, skin lesions, lung cancers, cardiovascular effects and anemia [21]. Metal ions, such as $\mathrm{Hg}(\mathrm{II}), \mathrm{Cr}$ (III), $\mathrm{Pb}$ (II), $\mathrm{Cd}(\mathrm{II}), \mathrm{Cu}$ (II) and $\mathrm{Ni}$ (II) ions are toxic to the aquatic systems. The removal of $\mathrm{Cr}(\mathrm{VI})$ using acid-catalysed chemical reduction to $\mathrm{Cr}^{3+}$ and then precipitation as hydroxide under alkaline conditions using either lime or caustic soda was reported [22]. The removal of $\mathrm{Cu}$ using CS and precipitation as copper hydroxide by liming was also reported $[23,24]$. Recently, the production of CSgelatin hydrogel effectively removed $\mathrm{Pb}$ (II), $\mathrm{Cd}(\mathrm{II}), \mathrm{Hg}$ (II) and $\mathrm{Cr}$ (III) contaminated in wastewater [25]. The effect of reaction parameters, such as temperature, solvent and reaction time on $\mathrm{Zn}$ (II) complexation with the Schiff base, ligand synthesized from salicylaldehyde and CS was reported [26]. The capacity of CS for the metal uptake of different metal ions was reported with different ratios. Sandhya and Tonni [27] had reported in their review article that CS showed highadsorption capacities of $\mathrm{Hg}(\mathrm{II}), \mathrm{Cr}(\mathrm{VI})$ and $\mathrm{Cd}(\mathrm{II})$ with 815 , 273 and $250 \mathrm{mg} \mathrm{g}^{-1}$, respectively.

This work is aimed at modifying CS in increasing the capacity and metal uptake selectivity. To the best of our knowledge, this is the first method to prepare these newly synthesized CS derivatives.
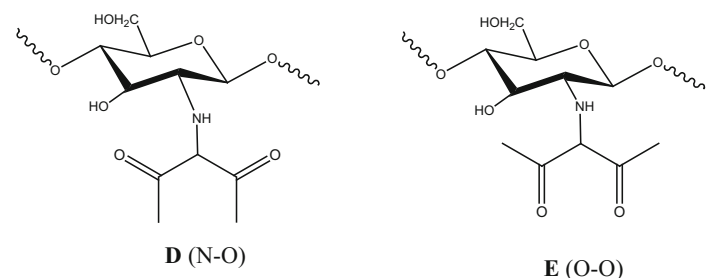

\section{Experimental}

\subsection{Materials}

3-chloro-2,4-pentanedione was used as received. All chemicals and metal salts were reagent grade and used without further purification.

Elemental analysis was investigated on LECO CHNS-932, at Analab, Faculty of Science, Kuwait University. Infrared (IR) spectra were recorded on a Perkin-Elmer System 2000 
FTIR spectrophotometer (Kyoto, Japan). Scanning electron microscopy was carried out at room temperature in a model JSM 6300 JEOL scanning electron microscope (Akishima, Japan) at $20 \mathrm{kV}$. Thermal analysis (TG) was carried out on a Shimadzu thermal system 50 consisting of TGA-50 and DTA-50 with a heating rate of $10^{\circ} \mathrm{C} \mathrm{min}^{-1}$ under a $\mathrm{N}_{2}$ atmosphere and a temperature range up to $800^{\circ} \mathrm{C}$. X-ray photoelectron spectroscopy (XPS) spectra were recorded on a Thermo ESCALAB $250 \mathrm{Xi}$ using monochromatic AlK $\alpha$ radiation $(1486.6 \mathrm{eV})$ with a spot size of $850 \mu \mathrm{m}$.

\subsection{Synthesis of CS-CPD: reaction of CS with} 3-chloro-2,4-pentanedione

3-chloro-2,4-pentanedione $(0.01 \mathrm{~mol})$ was added to $100 \mathrm{ml}$ of toluene containing a CS film $(5 \times 5 \mathrm{~cm})$ and sodium carbonate $(1.5 \mathrm{~g})$. The reaction mixture was refluxed for $8 \mathrm{~h}$. The produced modified CS derivative films were refluxed in ethanol for $1 \mathrm{~h}$. Elemental analysis of CS-CPD: C\%: 40.14, H\%: 6.88, N\%: 5.90; IR (KBr, $\left.v_{\max }, \mathrm{cm}^{-1}\right): 3389(\mathrm{OH}), 3286$, 3159 (NH), 2887, 2887 (CH-aliphatic), 1726, 1651 (CO).

\subsection{Synthesis of N-pyrazolylchitosan: reaction of CS-CPD} with hydrazine hydrate

The CS-CPD film $(5 \times 5 \mathrm{~cm})$ was added to $100 \mathrm{ml}$ DMF containing hydrazine hydrate $(0.01 \mathrm{~mol})$ and then, heated under reflux for $8 \mathrm{~h}$. The pyrazolylchitosan derivatives obtained were refluxed in ethanol for $1 \mathrm{~h}$. Elemental analysis: $\mathrm{C} \%$ : 44.01, H\%: 7.21, N\%: 10.69; IR (KBr, $\left.v_{\max }, \mathrm{cm}^{-1}\right)$ : 3364 , 3290, 3158 (OH and NH), 2887, 2887 (CH-aliphatic), 1651 (CO).

\subsection{Metal complexation}

The CS-CPD film $(5 \times 5 \mathrm{~cm})$ was submerged in a hot solution of metal nitrate salts $(0.01 \mathrm{~mol})$ in DMF and then, heated
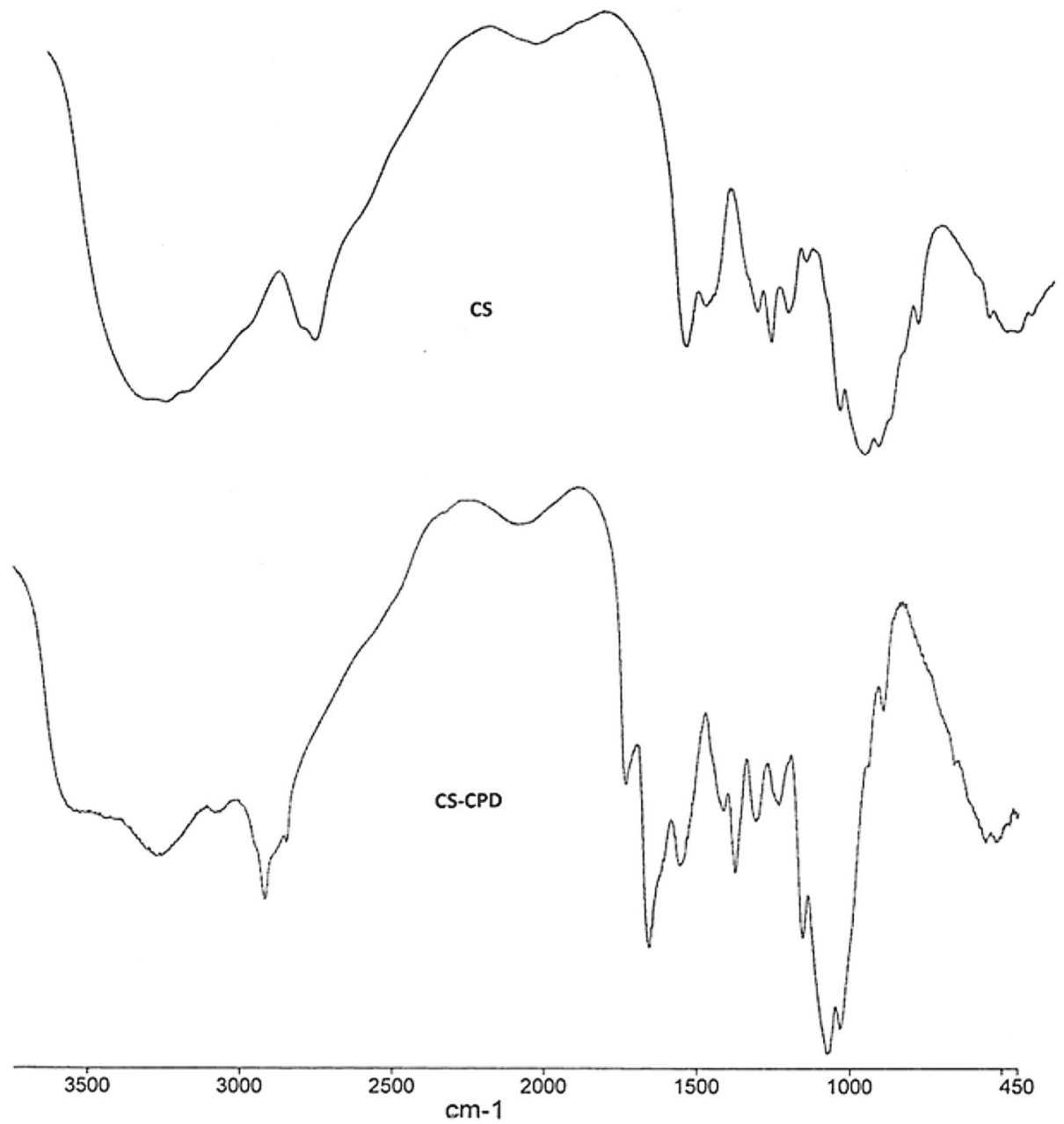

Figure 1. FTIR of CS and CS-CPD. 


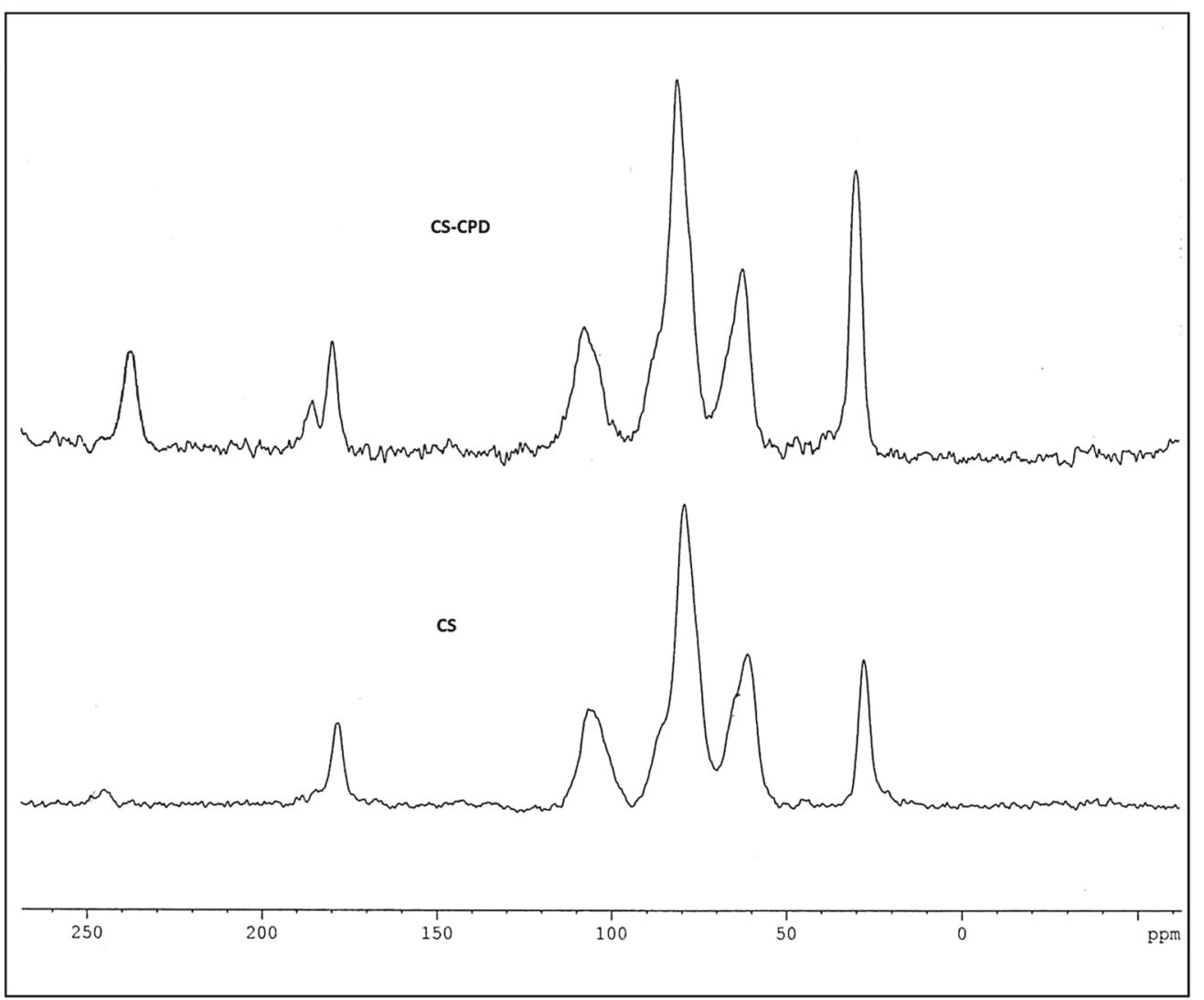

Figure 2. Solid NMR of CS and CS-CPD.

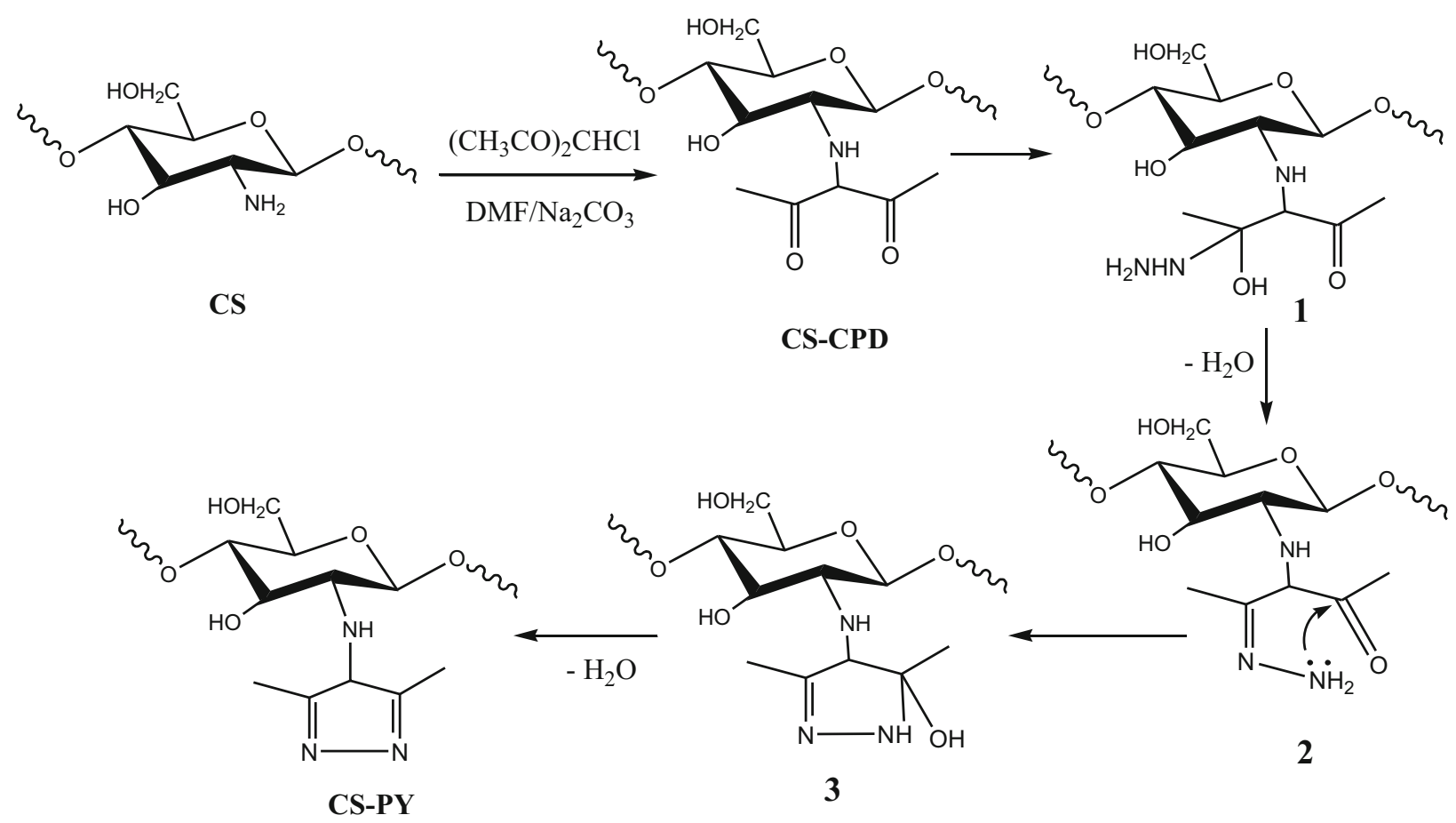

Scheme 1. Modification of CS with 3-chloro-2,4-pentanedione. 

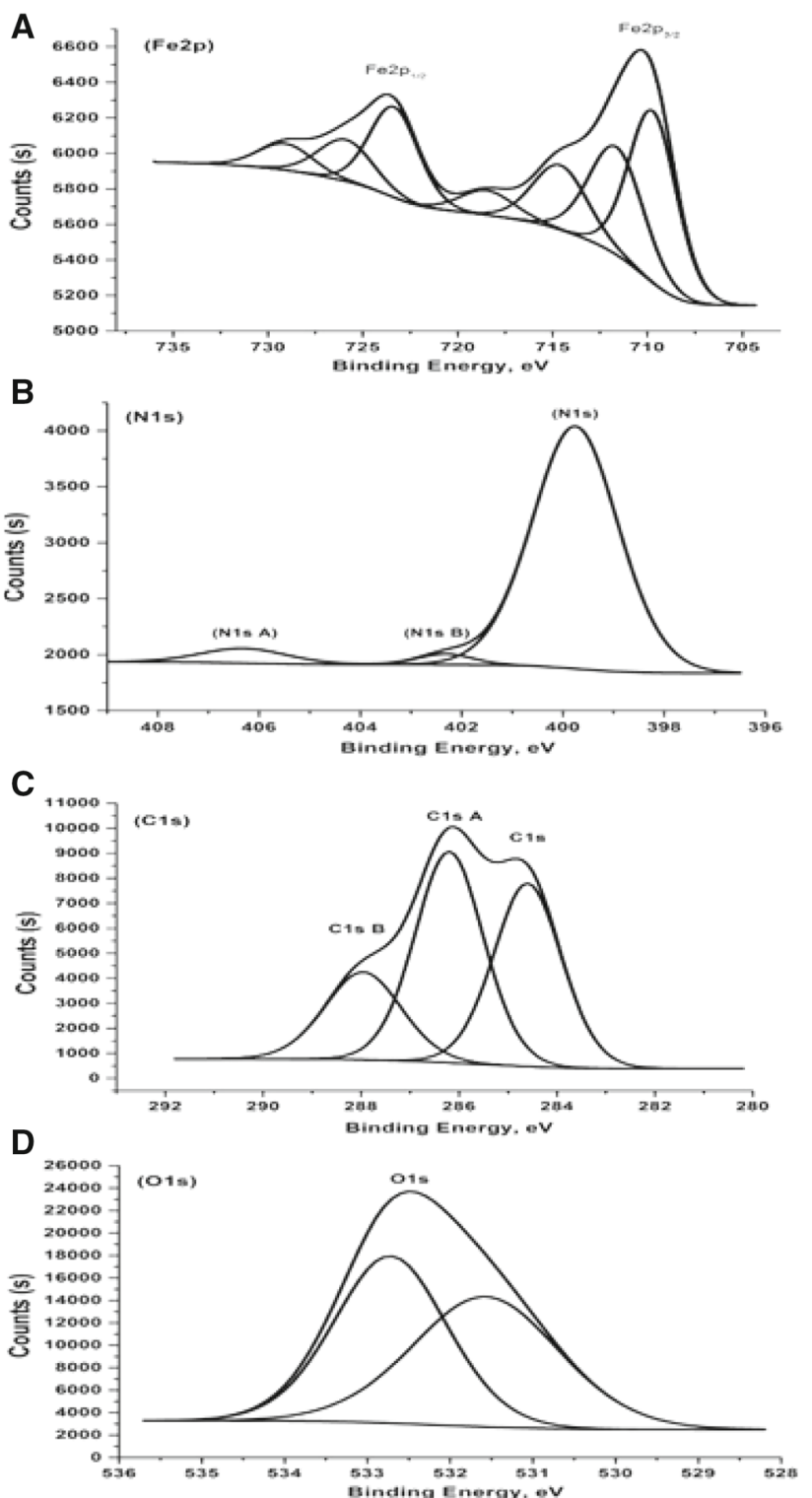

Figure 3. XPS data of the CS-CPD-Fe complex: (A) Fe peaks; (B) nitrogen peaks; $(\mathbf{C})$ carbon peaks and $(\mathbf{D})$ oxygen peaks.

under reflux for $5 \mathrm{~h}$. The obtained metallopolymer complex films were purified by heating in ethanol for $1 \mathrm{~h}$.

CS-CPD-Pb complex: elemental analysis: $\mathrm{C} \%$ : 40.62, $\mathrm{H} \%$ : 7.03, N\%: 6.67; IR (KBr, $\left.v_{\max }, \mathrm{cm}^{-1}\right)$ : br. $3550(\mathrm{OH}$ and $\mathrm{NH}), 2911$ (aliphatic-CH), 1727, 1559 (CO). CS-CPD-Hg complex: elemental analysis: C\%: 42.28, $\mathrm{H} \%: 8.02, \mathrm{~N} \%$ : 7.04; IR (KBr, $\left.v_{\max }, \mathrm{cm}^{-1}\right)$ : br. $3536(\mathrm{OH}$ and $\mathrm{NH}), 2975$ (aliphatic-CH), 1721, 1635 (CO). CS-CPD-Ca complex: elemental analysis: $\mathrm{C} \%$ : 39.26, H\%: 6.75, N\%: 6.97; IR (KBr, $\left.v_{\max }, \mathrm{cm}^{-1}\right): 3598(\mathrm{OH}$ and $\mathrm{NH}), 2822$ (aliphatic-CH), br. 1651-1622 (CO). CS-CPD-Co complex: elemental analysis: $\mathrm{C} \%$ : 27.70, $\mathrm{H} \%$ : 5.54, N\%: 8.62; IR (KBr, $\left.v_{\max }, \mathrm{cm}^{-1}\right): 3546$, 3375, 3307, 3260, 3205 (OH and NH), 2869 (aliphatic-CH),
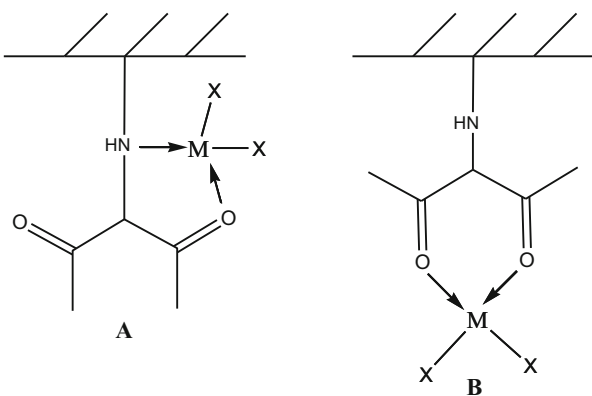

Scheme 2. Suggested complex structures with different metal ions: (A) complex with chelating centre $\mathrm{N}-\mathrm{O}$ and (B) complex with chelating centre $\mathrm{O}-\mathrm{O}$.

1633 (CO). CS-CPD-Cr complex: elemental analysis: C\%: 32.35, H\%: 6.14, N\%: 8.60; IR ( $\left.\mathrm{KBr}, v_{\max }, \mathrm{cm}^{-1}\right)$ : br. 3500 (OH and $\mathrm{NH}), 1725,1561$ (CO). CS-CPD-Fe complex: elemental analysis: $\mathrm{C} \%$ : 33.60, H\%: 6.30, N\%: 9.10; IR (KBr, $\left.v_{\max }, \mathrm{cm}^{-1}\right): 3449,3384,3322,3235,3138(\mathrm{OH}$ and $\mathrm{NH})$, 2976 (aliphatic-CH), 1725, 1620 (CO). CS-CPD-Ni complex: elemental analysis: C\%: 24.23, H\%: 5.16, N\%: 8.04; IR $\left(\mathrm{KBr}, v_{\max }, \mathrm{cm}^{-1}\right)$ : br. $3557(\mathrm{OH}$ and $\mathrm{NH}), 1675(\mathrm{CO})$.

\subsection{Ion selectivity}

A modified CS film $(5 \times 5 \mathrm{~cm})$ was added to aqueous solution containing $(0.01 \mathrm{~mol})$ a metal nitrate mixture $\left(\mathrm{M}=\mathrm{Pb}^{2+}, \mathrm{Hg}^{2+}, \mathrm{Ca}^{2+}, \mathrm{Co}^{2+}, \mathrm{Cr}^{3+}, \mathrm{Fe}^{3+}\right.$ or $\left.\mathrm{Ni}^{2+}\right)$ [28]. The mixture was stirred for $24 \mathrm{~h}$. Then, the reaction product were filtered, and the concentration of the metal ion and the blank solution were determined by inductively coupled plasma-optical emission spectrometry (ICP-OES) measurement.

\subsection{Treatment of Gulf water samples}

The real Gulf water sample (5 1) was pre-concentrated to a final volume of $150 \mathrm{ml}$. The metal ion concentration was determined by ICP-OES. The pre-concentrated sample was divided into three portions of $50 \mathrm{ml}$, followed by treating with the modified CS film under a shaking rate of $350 \mathrm{rpm}$ for $24 \mathrm{~h}$. The mixture was filtered and the polymer film was washed several times with double-distilled water. The results of ICP-OES measurements before and after treatment and the percentage of the metal uptake were estimated according to the following equation [29]:

$$
\text { Adsorption } \%=\frac{C_{\mathrm{i}}-C_{\mathrm{f}}}{C_{\mathrm{i}}} \times 100,
$$

where $C_{\mathrm{i}}$ and $C_{\mathrm{f}}$ are the initial and final concentrations of the metal ion ( $\mathrm{mg} \mathrm{l}^{-1}$ or $\mu \mathrm{gl}^{-1}$ ) before and after treatment, respectively. The results are the average of three measurements and precise to $\pm 1.25 \%$. 

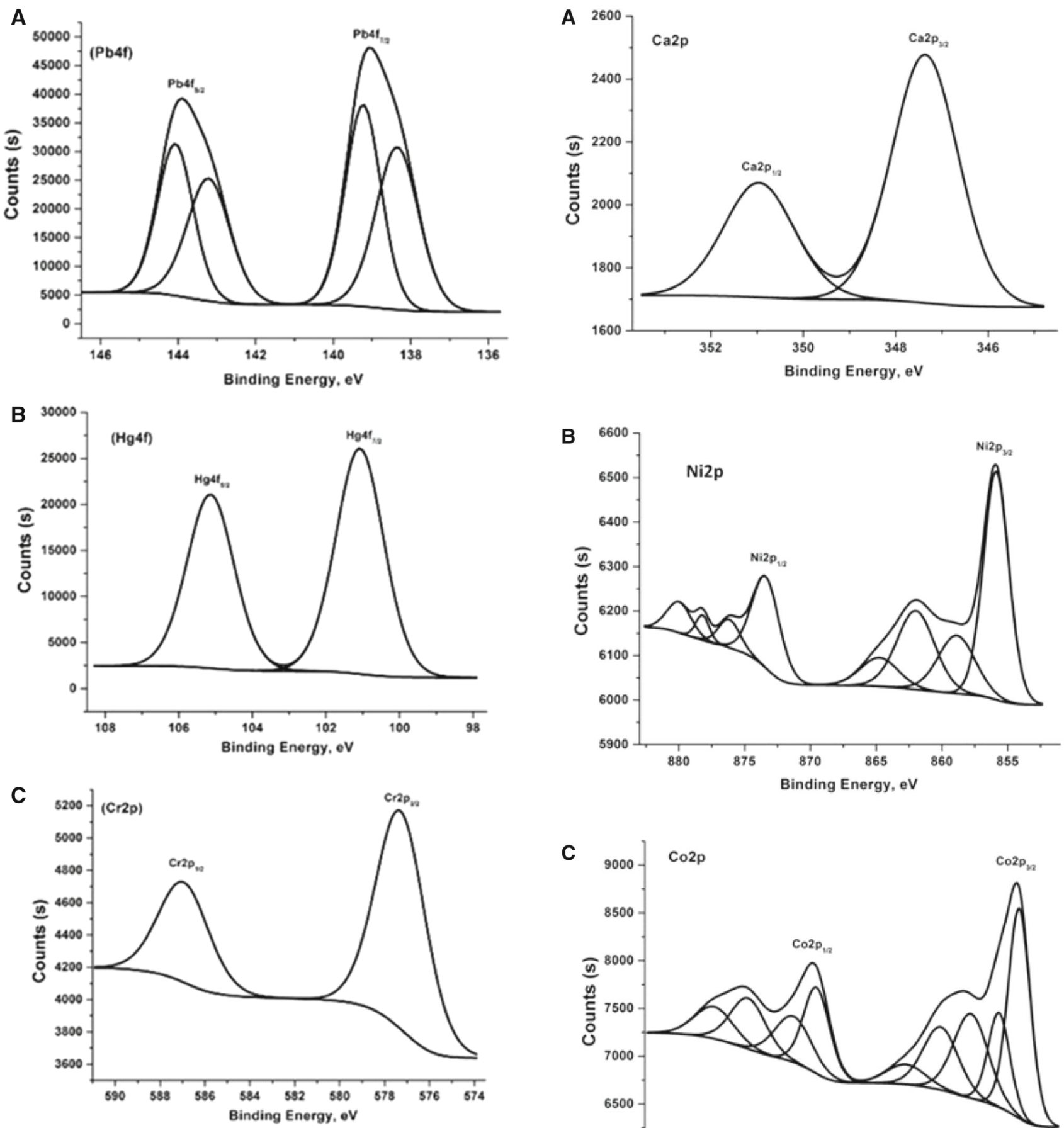

Figure 4. XPS data of the modified CS complex: (A) CS-CPD-Pb; (B) CS-CPD-Hg and (C) CS-CPD-Cr complexes.

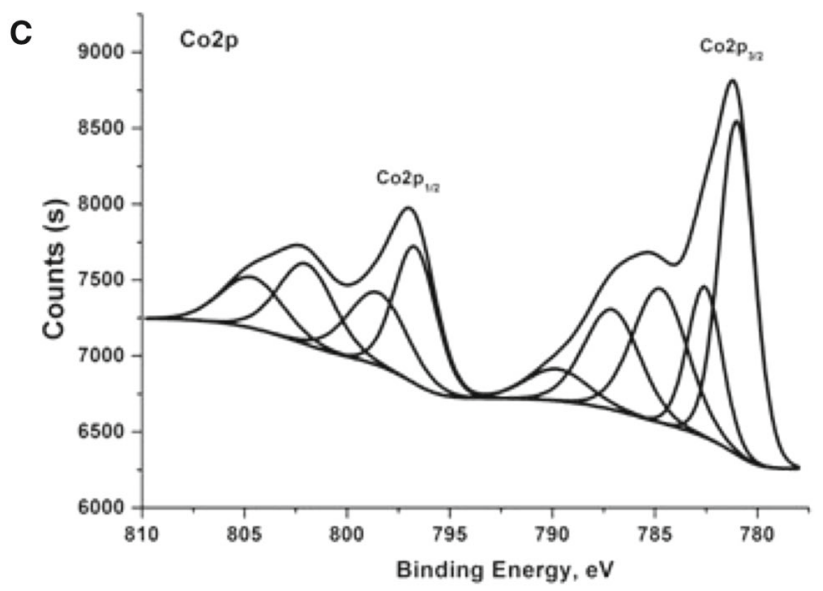

Figure 5. XPS data of the modified CS complex: (A) CS-CPD-Ca; (B) CS-CPD-Ni and (C) CS-CPD-Co complexes.

\section{Results and discussion}

\subsection{Modification and characterization of CS}

CS alkylated with 3-chloro-2,4-pentanedione in the presence of sodium carbonate to give $\mathrm{N}$-alkylated products CS-CPD. The reaction product was determined based on the

Fourier transform infrared (FTIR) spectrum (figure 1) which displayed two carbonyl bands at 1736 and $1651 \mathrm{~cm}^{-1}$. Furthermore, solid nuclear magnetic resonance (NMR) revealed the presence of the carbonyl group at $\delta 245.38 \mathrm{ppm}$ and the amide carbonyl group at $\delta 178.03 \mathrm{ppm}$ (figure 2). 
Table 1. Ion selectivity (ICP) of different metal ions from aqueous solution by CS-CPD.

\begin{tabular}{lcccc}
\hline Metal ion & $C_{\mathrm{i}}\left(\mathrm{mg} \mathrm{l}^{-1}\right)$ & $C_{\mathrm{f}}\left(\mathrm{mg} \mathrm{l}^{-1}\right)$ & $\left(C_{\mathrm{i}}-C_{\mathrm{f}}\right)$ & $\begin{array}{c}\text { Sorption } \\
(\%)\end{array}$ \\
\hline $\mathrm{Hg}$ & 165,398 & $13,400.80$ & $151,997.2$ & 91.89 \\
$\mathrm{Co}$ & 1836.00 & 151.84 & 1684.16 & 91.73 \\
$\mathrm{~Pb}$ & 3315.10 & 284.11 & 3030.99 & 91.43 \\
$\mathrm{Ca}$ & 1642.5 & 164.25 & 1478.25 & 90.00 \\
$\mathrm{Ni}$ & 2366.80 & 331.35 & 2035.45 & 86.00 \\
$\mathrm{Fe}$ & 2420.56 & 359.21 & 2061.35 & 85.16 \\
$\mathrm{Cr}$ & 2382.60 & 889.91 & 1492.69 & 62.65 \\
\hline
\end{tabular}

Table 2. ICP-OES results of the Gulf ocean water sample before and after treatment with the chelating polymer CS-CPD.

\begin{tabular}{lrrc}
\hline Metal ion & \multicolumn{1}{c}{$C_{\mathrm{i}}$} & \multicolumn{1}{c}{$C_{\mathrm{f}}$} & $\%$ of metal uptake \\
\hline $\mathrm{Na}^{+\mathrm{a}}$ & $16,427.550$ & 2506.550 & 84.742 \\
$\mathrm{~K}^{+\mathrm{a}}$ & 763.900 & 178.260 & 76.664 \\
$\mathrm{Mg}^{2+\mathrm{a}}$ & 1611.400 & 164.580 & 89.787 \\
$\mathrm{Ca}^{2+\mathrm{a}}$ & 509.500 & 16.870 & 96.689 \\
$\mathrm{Co}^{2+\mathrm{b}}$ & 2.540 & 0.273 & 89.252 \\
$\mathrm{Ni}^{2+\mathrm{b}}$ & 13.750 & 0.173 & 98.737 \\
$\mathrm{Cu}^{2+\mathrm{b}}$ & 13.700 & 0.154 & 98.876 \\
$\mathrm{Cd}^{2+\mathrm{b}}$ & $\mathrm{BDL}$ & $\mathrm{ND}$ & $\mathrm{ND}$ \\
$\mathrm{Pb}^{2+\mathrm{b}}$ & 74.200 & 25.148 & 66.108 \\
$\mathrm{Fe}^{3+\mathrm{b}}$ & 1.070 & 0.014 & 98.692 \\
$\mathrm{Hg}^{2+\mathrm{b}}$ & 15.100 & 0.885 & 94.139 \\
\hline
\end{tabular}

${ }^{\mathrm{a}} C_{\mathrm{i}}$ in $\mathrm{mg} 1^{-1}$; ${ }^{\mathrm{b}} C_{\mathrm{i}}$ in $\mu \mathrm{g} 1^{-1}$; ND, not detected; and BDL, below detection limit.

In addition, other carbons are present at 106.26, 85.30, 78.76, $64.69,60.88$ and $27.64 \mathrm{ppm}$. Moreover, the structure was confirmed via reaction of the polymeric derivative, CS-CPD with hydrazine hydrate to give pyrazolylchitosan derivatives (CSPY) (scheme 1). The reaction is self-catalysed by hydrazine hydrate. Thus, the reaction is believed to proceed via nucleophilic attack of the nitrogen lone pair to the carbonyl carbon to give non-isolated intermediates $\mathbf{1}$, followed by the loss of water molecules to give intermediate $\mathbf{2}$, further attack by the second nitrogen atom to the second carbonyl carbon and the loss of another water molecule leading to the formation of the final isolated compound CS-PY. The structure determined based on IR which revealed the absence of the carbonyl group at $1736 \mathrm{~cm}^{-1}$.

\subsection{Formation of complexes}

The modified CS was refluxed with a metal salt solution in a suitable solvent to give the corresponding complexes. The structures of the obtained complexes were determined based on elemental analysis, FTIR and XPS data. XPS of

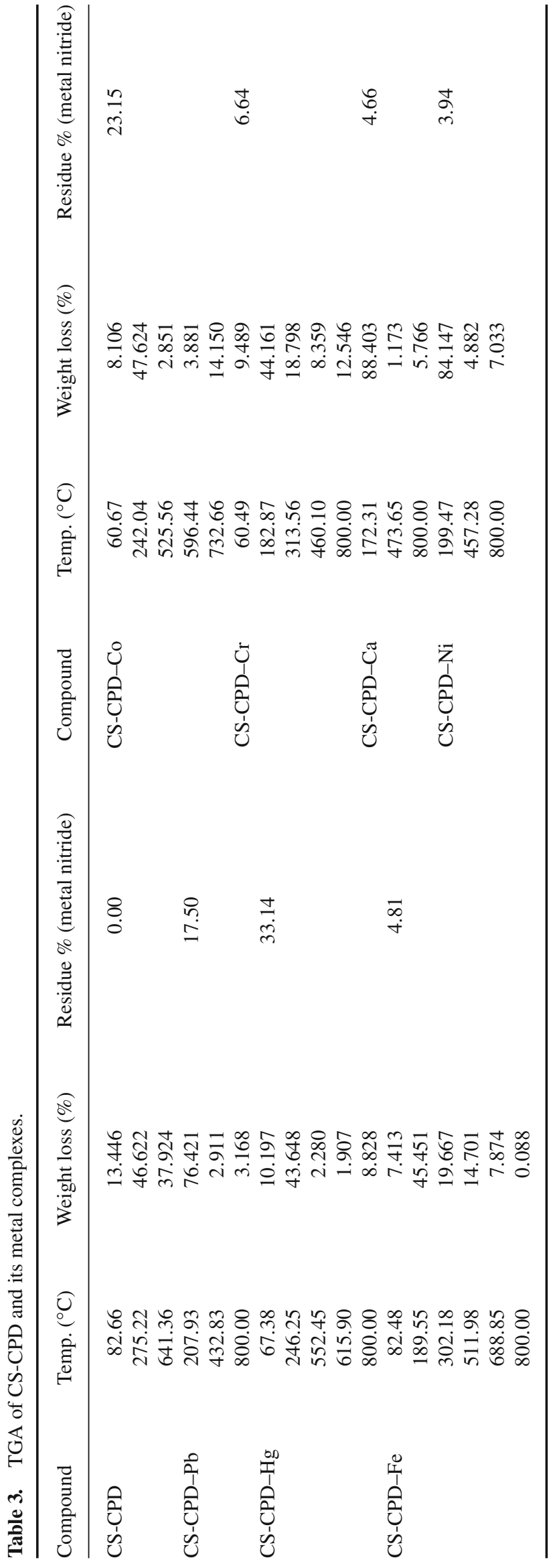


the metallopolymer confirmed the presence of metal and it refers to the centre of chelation, through studying the binding energy.

\section{$3.3 X P S$}

XPS was used to analyse the elemental states and contents in the sample. Figure 3A-D shows the survey spectra of Fe, $\mathrm{N}, \mathrm{C}$ and $\mathrm{O}$ in the modified polymer CS-CPD. The XPS spectra of $\mathrm{Fe}$ are shown in figure $3 \mathrm{~A}$, the peaks at 711 and $724.3 \mathrm{eV}$ are assigned to $\mathrm{Fe}(\mathrm{III}) 2 \mathrm{p}_{3 / 2}$ and $\mathrm{Fe}(\mathrm{III}) 2 \mathrm{p}_{1 / 2}$, respectively, denoting a band for $\mathrm{Fe}-\mathrm{O}$. The peak at a binding energy of 709.08 denoted a band for $\mathrm{Fe}-\mathrm{N}$ bond. The band of the $\mathrm{CS}$ complex at $399.5 \mathrm{eV}$ was attributed to the amino groups that were involved in the hydrogen bond $\left(\mathrm{NH}_{2}-\mathrm{O}\right.$ ) (figure 3B). The CS-Fe complex denoted a band for N1s at around $402 \mathrm{eV}$ (figure 3B). This band was assigned to the chelation

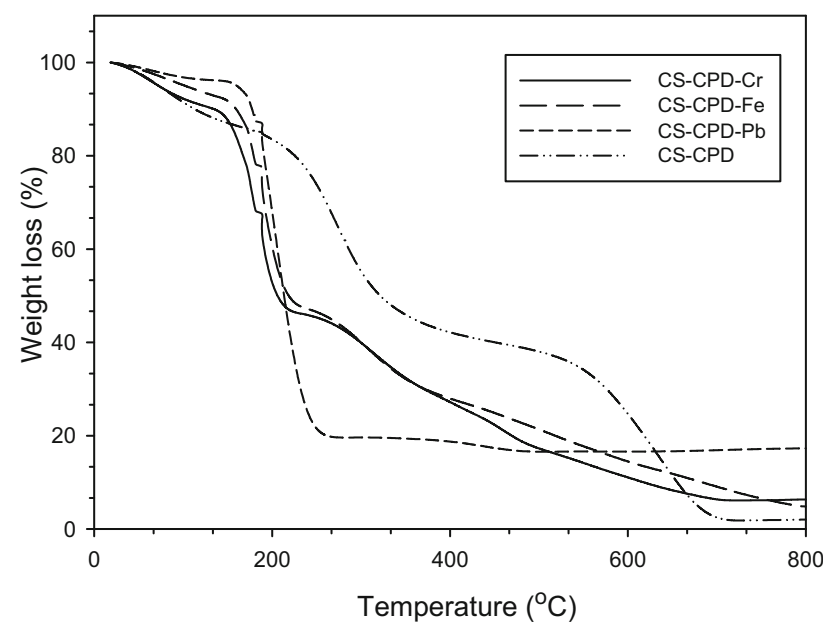

Figure 6. TGA curves of CS-CPD; CS-CPD-Cr; CS-CPD-Fe and CS-CPD-Pb.

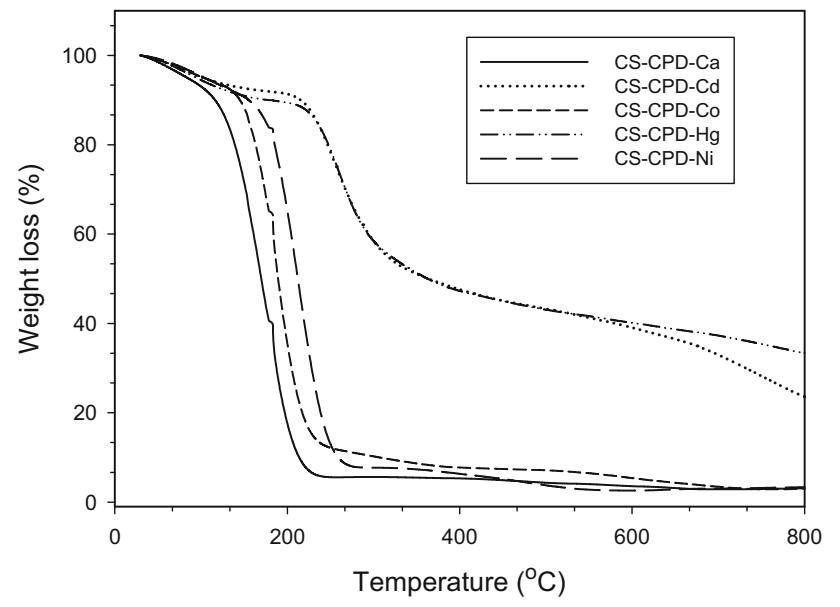

Figure 7. TGA curves of CS-CPD-Ca; CS-CPD-Cd; CS-CPD$\mathrm{Co}$; CS-CPD-Hg and CS-CPD-Ni. between the amino groups and iron ions $\left(\mathrm{NH}_{2}-\mathrm{Fe}\right)$. Figure $3 \mathrm{C}$ shows the $\mathrm{C} 1 \mathrm{~s}$ peak of the $\mathrm{CS}$-complex, main peak at $284.4 \mathrm{eV}$, which is ascribed to the presence of $\mathrm{C}=\mathrm{C} / \mathrm{C}-\mathrm{C} \mathrm{sp}{ }^{2}$ carbon atoms in the framework. The peaks at 286.5 and $287.6 \mathrm{eV}$ correlate with the carbon in $\mathrm{C}-\mathrm{O}$ and the carbonyl carbon in $\mathrm{C}=\mathrm{O}$, respectively. The $\mathrm{O} 1 \mathrm{~s}$ peaks at $531.6 \mathrm{eV}$ (figure 3D) was assigned to $\mathrm{N}-\mathrm{C}-\mathrm{O}$ chemical bindings in $\mathrm{N}$-acetylated-glucosamine units. The peaks at $531.5 \mathrm{eV}$ corresponded to free hydroxyl groups of CS. In light of this information, structure (A) (scheme 2) can be assigned to the complex structure.

The XPS spectra for all metal complexes with modified CS are presented in figure 4A-C. Figure 4A shows the detailed spectra of $\mathrm{Pb}$ peaks, produced from the reaction of CS-CPD with lead nitrate, appearing at $138,139.23 \mathrm{eV}\left(\mathrm{Pb} \mathrm{4f}_{7 / 2}\right)$ and

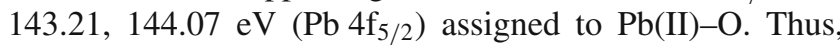
structure B (scheme 2) was assigned as a reaction product.

Figure 4B shows XPS spectra produced from the reaction of modified polymer CS-CPD with $\mathrm{Hg}$ (II). The high-resolution spectra of $\mathrm{Hg}(\mathrm{II})$ (figure 4B) exhibited two peaks at 101.08 and $105.14 \mathrm{eV}$ assigned to $\mathrm{Hg} 4 \mathrm{f}_{7 / 2}$ and $\mathrm{Hg} 4 \mathrm{f}_{5 / 2}$, respectively $\left(\mathrm{Hg}^{2+}\right)$. This may indicate that the $\mathrm{Hg}$ is embedded in the polymeric chain.

Figure 4C shows the XPS spectra produced from the reaction of modified polymer CS-CPD with $\mathrm{Cr}$ (III). Two peaks for $\mathrm{Cr}$ (figure 4C) centred at 577.28 and $586.95 \mathrm{eV}$ were resolved for the $\mathrm{Cr} 2 \mathrm{p}_{3 / 2}$ and $\mathrm{Cr} 2 \mathrm{p}_{1 / 2}$ peaks, respectively, and assigned to the $\mathrm{Cr}(\mathrm{III})-\mathrm{O}$ bond. Thus, structure $\mathrm{B}$ (scheme 2) was assigned as the complex product.

Figure 5A shows the high-resolution XPS spectra of the $\mathrm{Ca}$ $2 \mathrm{p}$ core levels. Two peaks were seen, identified as $\mathrm{Ca} 2 \mathrm{p}_{1 / 2}$ and $\mathrm{Ca} 2 \mathrm{p}_{3 / 2}$, in the order of increasing binding energy. $\mathrm{Ca} 2 \mathrm{p}_{3 / 2}$ at 347.3 is a typical binding energy of the $\mathrm{Ca}^{2+}$ ion. The narrow and sharp peaks indicate that $\mathrm{Ca}$ is connected with $\mathrm{O}[30,31]$. Structure B (scheme 2) was assigned as a reaction product.

The Ni $2 p$ region (figure $5 \mathrm{~B}$ ) has complex multiple split peaks. The $\mathrm{Ni}_{3 / 2}$ main peak and its satellite at 855.6 and $862.5 \mathrm{eV}$, and the $\mathrm{Ni} 2 \mathrm{p}_{1 / 2}$ main peak and its satellite at 874 and 880 , respectively, are assigned to the $\mathrm{Ni}-\mathrm{O}$ bond. Structure B (scheme 2) was assigned as a reaction product.

The Co $2 \mathrm{p}$ peak (figure $5 \mathrm{C}$ ) has significantly split spinorbit components. The presence of $\mathrm{Co}-\mathrm{O}$ could demonstrate two peaks located at binding energies of $781\left(\mathrm{Co} 2 \mathrm{p}_{3 / 2}\right)$ and 796.6 (Co $\left.2 \mathrm{p}_{1 / 2}\right)$ eV. Two-satellite $\mathrm{Co}-\mathrm{O}$ peaks are observed at binding energies of $804.6 \mathrm{eV}$ for $\mathrm{Co} 2 \mathrm{p}_{3 / 2}$ and $796.7 \mathrm{eV}$ for $\mathrm{Co} 2 \mathrm{p}_{1 / 2}$. The peak at a binding energy of $802 \mathrm{eV}$ may be assigned to the $\mathrm{Co}-\mathrm{N}$ bond [32]. Structure A (scheme 2) was assigned as a reaction product.

\subsection{Ion selectivity}

A mixture of nine metal salts was treated with modified polymer films. The ICP-OES measurements for the blank 

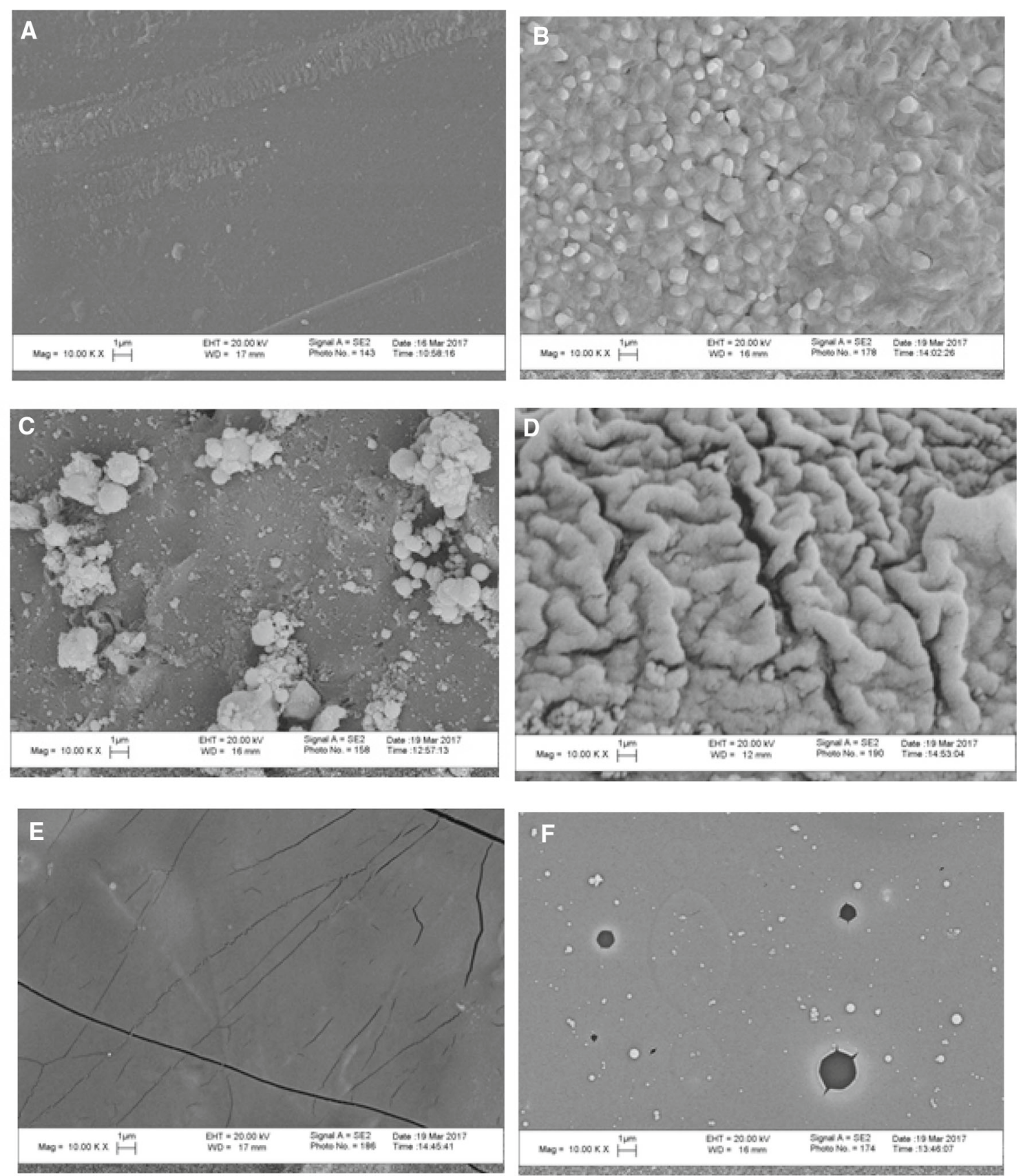

Figure 8. SEM images with 10,000 magnification: (A) CS-CPD; (B) CS-CPD-Pb; (C) CS-CPD-Hg; (D) CS-CPD-Cr; (E) CS-CPD-Ca and (F) CS-CPD-Fe complexes.

solution and the solution after $24 \mathrm{~h}$ treatment with different films were carried out. The differences refer to the metal uptake value. The ICP-OES measurements before and after treatment and the percentage of the metal uptake are shown in table 1 and are computed according to equation (1). Atomic absorption measurements for a mixture of the modified polymers, CS-CPD with a mixture of metal nitrate, $\mathrm{M}=\mathrm{Pb}^{2+}, \mathrm{Hg}^{2+}, \mathrm{Ca}^{2+}, \mathrm{Co}^{2+}, \mathrm{Cr}^{3+}, \mathrm{Fe}^{3+}$ or $\mathrm{Ni}^{2+}$ before and after treating with the polymer are also presented in table 1 . The polymer selectivity order of the modified polymer, CS-CPD can be arranged as follows:

$$
\mathrm{Hg}>\mathrm{Co}>\mathrm{Pb}>\mathrm{Ca}>\mathrm{Ni}>\mathrm{Fe}>\mathrm{Cr} \text {. }
$$

It is clear from the data that the highly selected ions by CSCPD are $\mathrm{Hg}^{2+}$ (91.89\%), $\mathrm{Co}^{2+}(91.73 \%), \mathrm{Pb}^{2+}(91.43 \%)$ and $\mathrm{Ca}^{2+}(90 \%)$. The high selectivity of the $\mathrm{Hg}$ ion may be due to the fitting of the $\mathrm{Hg}$ ion with the chelating centre. In a 

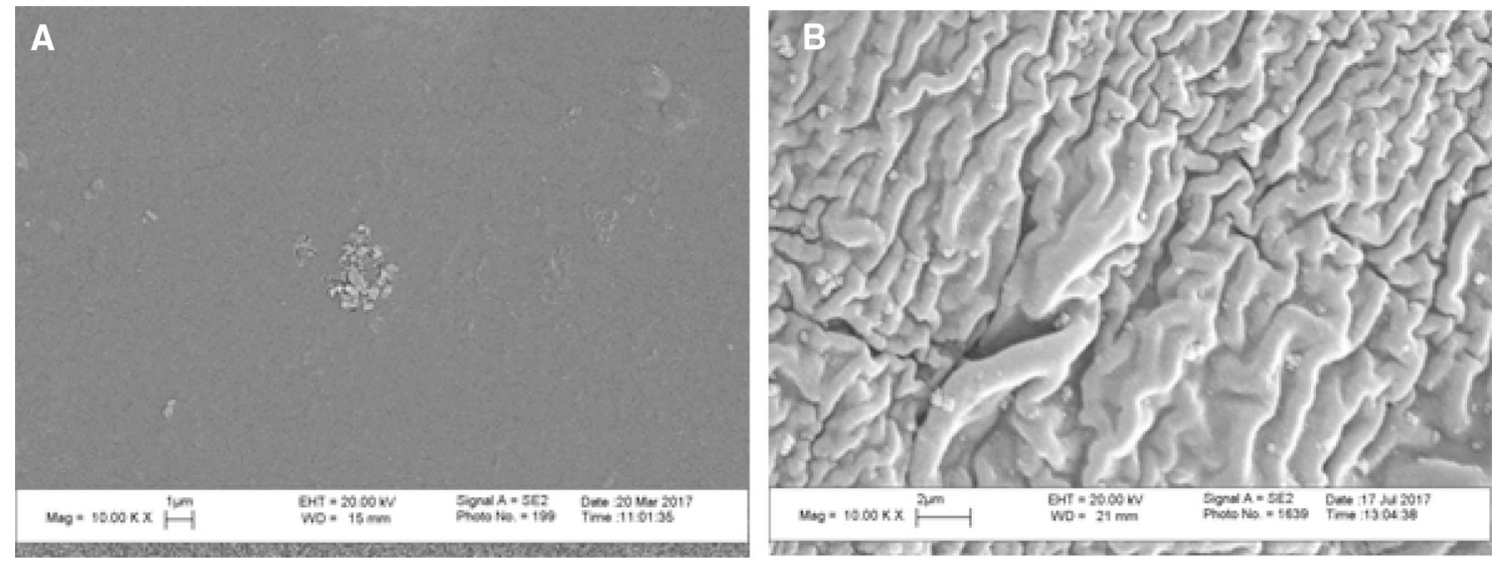

Figure 9. SEM images with 10,000 magnification: (A) CS-CPD-Ni and (B) CS-CPD-Co.

comparative study, the metal uptake of the modified CS showed more uptake than that of $\mathrm{CS}$ in the case of $\mathrm{Hg}, \mathrm{Pb}, \mathrm{Co}$ and $\mathrm{Ca}$. A little difference was observed in the case of $\mathrm{Ni}, \mathrm{Fe}$ and $\mathrm{Cr}$ about $1-1.5 \%$ more.

\subsection{Metal ions determination in Gulf water}

The use of the modified polymer for the Gulf ocean water analysis showed that the CS-CPD could uptake various metal ions (such as $\mathrm{Na}, \mathrm{K}, \mathrm{Mg}, \mathrm{Ca}, \mathrm{Co}, \mathrm{Ni}, \mathrm{Cu}, \mathrm{Cd}, \mathrm{Pb}, \mathrm{Fe}$ and $\mathrm{Hg}$ ) from the Gulf ocean water. The $\mathrm{Cu}, \mathrm{Ni}, \mathrm{Fe}, \mathrm{Hg}$ and $\mathrm{Co}$ ions were measured in $\mu \mathrm{g}^{-1}$, while $\mathrm{Na}, \mathrm{K}, \mathrm{Mg}$ and Ca ions were measured in $\mathrm{mg}^{-1}$. The ICP-OES measurements before and after treatment and the sorption percentage of the chelating polymer are presented in table 2 and are calculated according to equation (1).

\subsection{TGA analysis}

Thermogravimetric analysis (TGA) is an easy method to study the thermal stability or thermal degradation behaviour where the weight loss of the sample is measured continuously, whereas the temperature is changed at a constant rate of $10^{\circ} \mathrm{C} \mathrm{min}{ }^{-1}$. Table 3 and figures 6 and 7 show the thermal decomposition temperatures of modified CS and its complexes with different metals. The weight loss percentage for the CS and its metal complexes in the temperature $<200^{\circ} \mathrm{C}$ were due to the loss of absorbed or adsorbed water, in addition to H-bonding in the polymeric material [33]. In the case of modified CS, the maximum loss at $275.22^{\circ} \mathrm{C}$ was $46.62 \%$. In general, the weight loss increases with an increase in the temperature. The comparison of the maximum weight loss with the temperature between different metallopolymer complexes shows that the Hg-complex is the highest one and the Ca-complex is the lowest one. The remaining metal nitride is arranged as follows:

$$
\mathrm{Hg}>\mathrm{Co}>\mathrm{Pb}>\mathrm{Cr}>\mathrm{Fe}>\mathrm{Ca}>\mathrm{Ni} .
$$

The temperature, weight loss and residual percentages are indicated in table 3.

\subsection{Morphology and structures}

The change in the surface morphology may be due to the introduction of the metal ions in the polymer matrix or CS modification. SEM was carried out to confirm the chelation of the metal ions with the modified polymer, in addition, to study how the change in surface occurred. The morphologies of modified CS and polymer metal complexes with different metal ions are shown in figures 8 and 9 with 10,000 magnifications. CS shows a smooth surface, while CS-CPD-Pb, CS-CPD-Hg and CS-CPD-Cr showed dramatic surface changes. This means that the chelation mostly occurred on the surface of the polymer. On the other hand, the smooth surface may be due to the penetration of the metal ion and stronger embedding of metal ions in the matrix of the polymer than the others. Figure 8A shows the SEM micrograph of CS-CPD. The modification with 3-chloro-2,4pentanedione makes a little change in the surface as compared to the CS surface. The SEM micrograph of the CS-CPD$\mathrm{Pb}$ complex (figure 8B) shows a dramatic change in the surface as well as after metal complexation was generated which confirms the formation of the metal complex in agreement with the XPS data. The surface has a regular cubic shape. The SEM micrograph of the CS-CPD-Hg complex (figure 8C) seems to be clear as it appears from a non-uniform growth of the complex at different places on the surface. The SEM micrograph of the CS-CPD-Cr complex (figure 8D) shows an extreme change as compared with that of the CSCPD surface. Magnification at 10,000 is very specific as its shape seems to be like tubes. The SEM micrograph of CS-CPD-Ca shows a uniform surface with a little change 

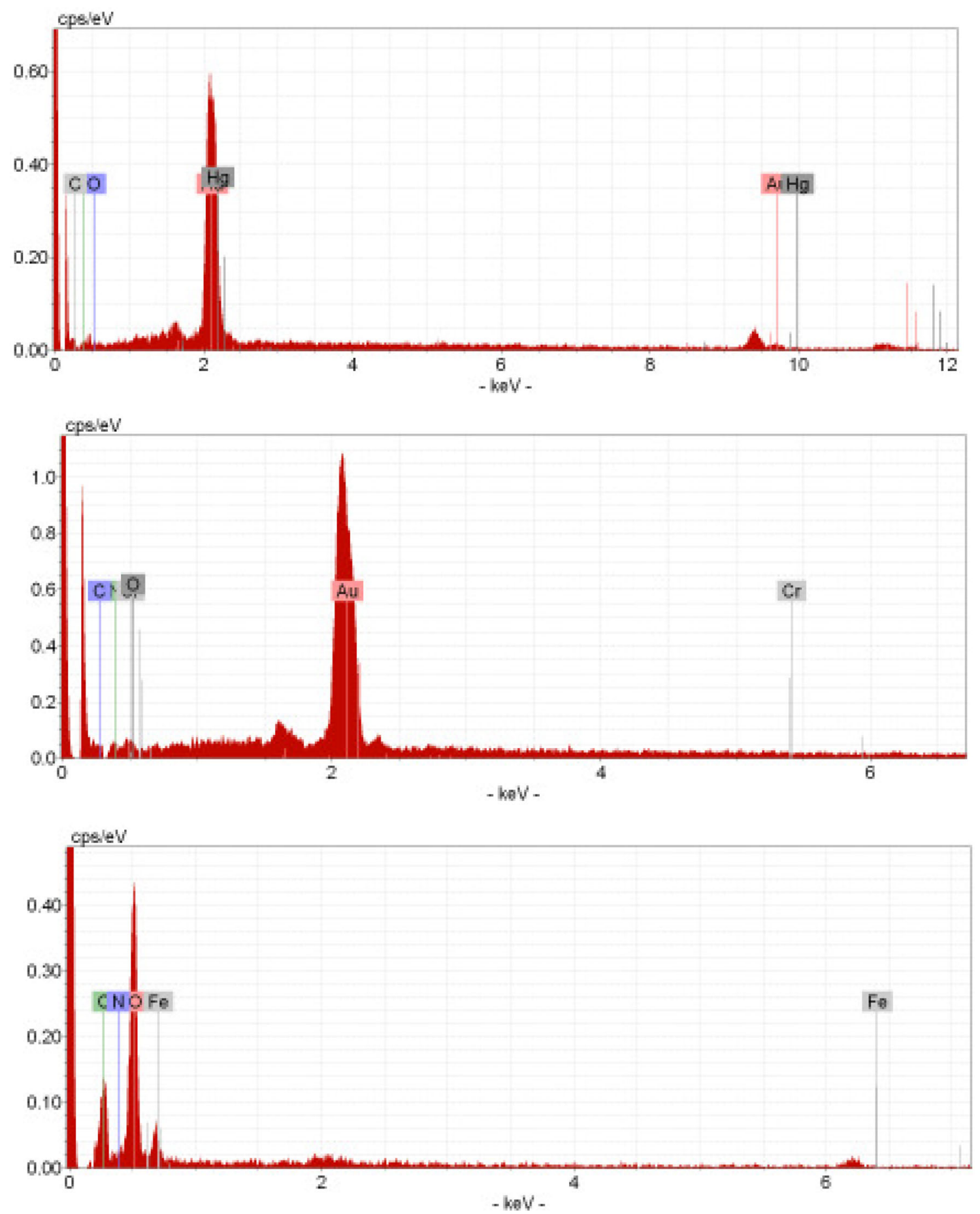

Figure 10. EDS analysis for CS-CPD-Hg, CS-CPD-Cr and CS-CPD-Fe.

as compared to $\mathrm{CS}-\mathrm{CPD}$ (figure $8 \mathrm{E}$ ). Figure $8 \mathrm{~F}$ shows the SEM micrograph of CS-CPD-Fe complex. Black spots which seem to be emitted in addition to white spots surrounded by black shades were observed. The SEM micrograph of CSCPD-Ni shows a little change (figure 9A), while the SEM micrograph of the CS-CPD-Co complex shows a tube-shaped structure similar to that in the case of the CS-CPD-Cr complex (figure 9B).

\subsection{EDX or EDAX analysis}

Energy-dispersive X-ray (EDX or EDAX) is an analytical technique used for the chemical characterization of a sample. On the other hand, this technique was used for analysis and it confirms the presence of metal ions. Figure 10 shows the energy-dispersive spectroscopy (EDS) spectra of the metal complexes CS-CPD-Fe, CS-CPD-Hg and CS-CPD-Cr. 

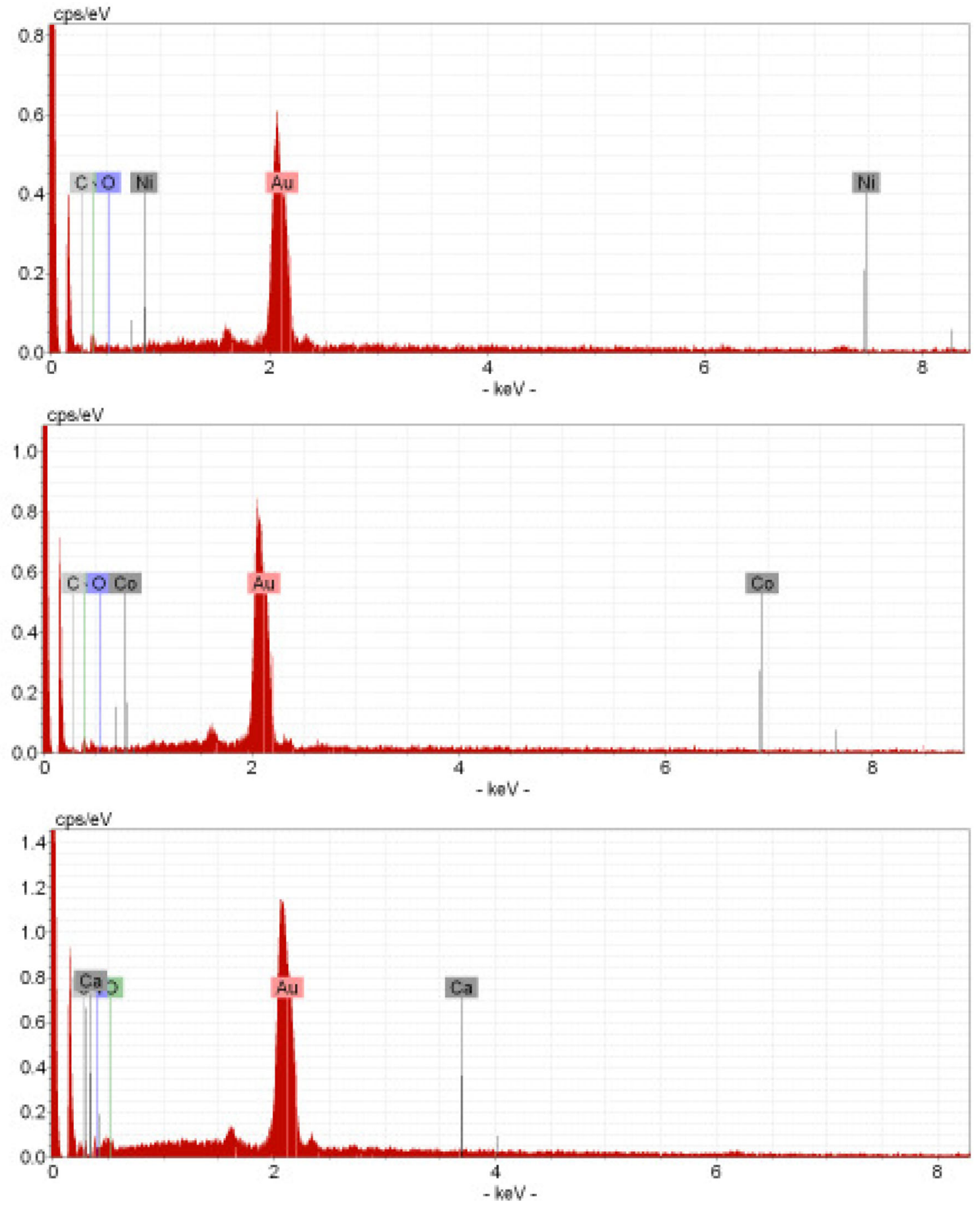

Figure 11. EDS analysis for CS-CPD-Ni, CS-CPD-Co and CS-CPD-Ca.

In addition, figure 11 shows the EDS spectra of the metal complexes CS-CPD-Co, CS-CPD-Ni and CS-CPD-Ca. The data obtained confirm the metal uptake and reveal the presence of a metal complex. The uptake of all metal ions by the polymer matrix, in addition to other atoms, was confirmed by EDS spectra.

\section{Conclusions}

In this study, CS was able to update through modification under normal conditions. The modifications carried out by the reaction of 3-chloro-2,4-pentanedione with the amino group as an active site in CS. The use of the modified CS in waste 
treatment was investigated. The data showed that the modified CS was selective for some metallic ions depending on the type of chelating centres $\mathrm{N}-\mathrm{O}$ and $\mathrm{O}-\mathrm{O}$. The metal ions $\mathrm{Fe}$ and $\mathrm{Co}$ preferred the $\mathrm{N}-\mathrm{O}$ chelating centre, while $\mathrm{Pb}, \mathrm{Cr}, \mathrm{Ni}$ and $\mathrm{Ca}$ preferred the $\mathrm{O}-\mathrm{O}$ chelating centre.

\section{Acknowledgements}

We kindly acknowledge the financial support on this project from the Research Administration of the Kuwait University through research project grant SC 12/15. The analytical services provided by the ANALAB and SAF in the faculty of Science through the grant nos. GS-01/01, GS 01/05 and GS 03/08 are also gratefully acknowledged.

\section{References}

[1] Chen B, Zhao H, Chen S, Long F, Huang B, Yang B et al 2019 Chem. Eng. J. (Amsterdam, Neth.) 35669

[2] Molnar A 2019 Coord. Chem. Rev. 388126

[3] Ye C-C, An Q-F, Wu J-K, Zhao F-Y, Zheng P-Y and Wang N-X 2019 Chem. Eng. J. (Amsterdam, Neth.) 359994

[4] Ma C, Li F, Wang C, He M, Shen C, Sand W et al 2018 Environ. Chem. 15267

[5] Liu W, Qin Y, Liu S, Xing R, Yu H, Chen X et al 2018 Sci. Rep. 81

[6] Lebedeva N S, Gubarev Y A, Yurina E S, Vyugin A I and Lipatova I M 2017 Russian J. Gen. Chem. 872327

[7] Pestov A and Bratskaya S 2016 Molecules 21330

[8] Cheung R C F, Ng T B, Wong J H and Chan W Y 2015 Mar. Mar Drugs 135156

[9] Li B, Fang Y, Shan C L, Ibrahim M, Xie G L, Wang Y L et al 2013 Asian J. Chem. 25891

[10] Hadi A G 2012 Br. J. Sci. 533

[11] Mekahlia S and Bouzid B 2009 Physics procedia (Proceedings of the JMSM 2008 Conference) 21045
[12] Badawy M E I and El-Aswad A F 2012 Plant Protect. Sci. 48 131

[13] Wang X, Du Y and Liu H 2004 Carbohydr. Polym. 5621

[14] Issam S, Adele M-G, Adele C-P, Stephane G and Veronique C 2005 J. Food Sci. 70 S102

[15] Higazy A, Hashem M, Elshafei A, Shaker N and Abdel Hady M 2010 Carbohydr. Polym. 79867

[16] Wang X, Du Y, Fan L, Liu V and Hu Y 2005 Polym. Bull. 55 105

[17] Kyoon H, Park N Y, Lee S H and Meyers S P 2002 Int. J. Food Microbiol. 7465

[18] Sy Q, Daj W and Forster Cf 1998 Water SA 24251

[19] Ahmad A, Ghufran R and Faizal W M 2010 Clean-Soil, Air, Water 38153

[20] Zhang L, Zeng Y and Cheng Z 2016 J. Mol. Liq. 214175

[21] Fu F and Wang Q 2011 J. Environ. Manage. 92407

[22] Iyengar U and Avs P R 1990 J. Appl. Polym. Sci. 39739

[23] Findon A, Mckay G and Blair H S 1993 J. Environ. Sci. Health: Part A 28173

[24] Schmuhl R, Krieg H M and Keizer K 2001 Water SA 27 1

[25] Jung In U and Lone S 2019 Repub. Korean Kong kae Taeho Kongbo, KR 2019027661 A 20190315

[26] Barbosa H F G and Cavalheiro E T G 2019 Int. J. Biol. Macromol. 1211179

[27] Sandhya B and Tonni A K 2003 J. Hazard. Mater. B97 219

[28] Elassar A-Z A, Al-Fulaij O A and El-Sayed A E M 2010 J. Polym. Res. 17447

[29] Elassar A-Z A, El-Dissouky A, Jeragh B, Buolian A H and Rizk S 2010 J. Chem. Eng. Data 554830

[30] Comans RN J, Eighmy T T and Shaw E L 1996 Surf. Sci. Spectra 4150

[31] Dalai M K, Kundu R, Pal P, Bhanja M, Sekhar B R and Martin C 2011 J. Alloys Compd. 5097674

[32] Jiang Y, Lu Y, Wang X, Bao Y, Chen W and Niu L 2014 Nanoscale 615066

[33] El-Dissouky A, Elassar A-Z A and Abdul-Hadi B-O 2011 J. Chem. Eng. Data 561827 